\title{
Effect of a structurally modified human granulocyte colony stimulating factor, G-CSFa, on leukopenia in mice and monkeys
}

\author{
Yongping Jiang ${ }^{1}$, Wenhong Jiang ${ }^{1}$, Yuchang Qiu ${ }^{1}$ and Wei Dai ${ }^{2^{*}}$
}

\begin{abstract}
Background: Granulocyte colony stimulating factor (G-CSF) regulates survival, proliferation, and differentiation of neutrophilic granulocyte precursors, Recombinant G-CSF has been used for the treatment of congenital and therapy-induced neutropenia and stem cell mobilization. Due to its intrinsic instability, recombinant G-CSF needs to be excessively and/or frequently administered to patients in order to maintain a plasma concentration high enough to achieve therapeutic effects. Therefore, there is a need for the development of G-CSF derivatives that are more stable and active in vivo.

Methods: Using site-direct mutagenesis and recombinant DNA technology, a structurally modified derivative of human G-CSF termed G-CSFa was obtained. G-CSFa contains alanine 17 (instead of cysteine 17 as in wild-type GCSF) as well as four additional amino acids including methionine, arginine, glycine, and serine at the aminoterminus. Purified recombinant G-CSFa was tested for its in vitro activity using cell-based assays and in vivo activity using both murine and primate animal models.

Results: In vitro studies demonstrated that G-CSFa, expressed in and purified from E. coli, induced a much higher proliferation rate than that of wild-type G-CSF at the same concentrations. In vivo studies showed that G-CSFa significantly increased the number of peripheral blood leukocytes in cesium-137 irradiated mice or monkeys with neutropenia after administration of clyclophosphamide. In addition, G-CSFa increased neutrophil counts to a higher level in monkeys with a concomitant slower declining rate than that of G-CSF, indicating a longer half-life of GCSFa. Bone marrow smear analysis also confirmed that G-CSFa was more potent than G-CSF in the induction of granulopoiesis in bone marrows of myelo-suppressed monkeys.
\end{abstract}

Conclusion: G-CSFa, a structurally modified form of G-CSF, is more potent in stimulating proliferation and differentiation of myeloid cells of the granulocytic lineage than the wild-type counterpart both in vitro and in vivo. G-CSFa can be explored for the development of a new generation of recombinant therapeutic drug for leukopenia.

\section{Background}

Granulocyte colony stimulating factor (G-CSF) is the principal cytokine that regulates survival, proliferation, and differentiation of neutrophilic granulocyte precursors [1-3], and it functionally activates mature blood neutrophils as well [4-7]. Among the family of colonystimulating factors, G-CSF is the predominant inducer of terminal differentiation of granulocytes [8]. Recombinant human G-CSF has been used as a therapeutic drug

\footnotetext{
* Correspondence: wei.dai@nyumc.org

${ }^{2}$ New York University School of Medicine, Tuxedo, NY, USA

Full list of author information is available at the end of the article
}

for leukopenia of cancer patients who receive myelosuppressive radio-or chemotherapy $[9,10]$. In recent years, recombinant G-CSF has also been used for the treatment of congenital neutropenia and stem cell mobilization $[11,12]$. It has been more than fifteen years since recombinant G-CSF was successfully used in the clinics. Due to its intrinsic instability, G-CSF needs to be excessively and/or frequently administered to patients in order to maintain a plasma concentration high enough to achieve therapeutic effects. This administration regimen not only causes inconvenience and pains in patients but also increases the chance for infections. Therefore, there is a necessity for the development of
() Biomed Central

(c) 2011 Jiang et al; licensee BioMed Central Ltd. This is an Open Access article distributed under the terms of the Creative Commons Attribution License (http://creativecommons.org/licenses/by/2.0), which permits unrestricted use, distribution, and reproduction in any medium, provided the original work is properly cited. 
G-CSF derivatives that are more stable and active in vivo. Here, we report that G-CSFa, a recombinant GCSF derivative, exhibits potent biological activities both in vivo and in vitro and that these activities appear to result from an enhanced stability of modified G-CSF and its binding affinity to the cognate receptor.

\section{Methods}

\section{Animals}

Male BALB/CICR C57 mice with an average weight of $22.5 \pm 1.2 \mathrm{~g}(20.0 \sim 24.9 \mathrm{~g})$, and monkeys with an average weight of $(5.4 \pm 1.0 \mathrm{~kg})$ were selected for our studies. Animals were housed in individual stainless steel cages in a study room with a regulated temperature of $24 \pm 2{ }^{\circ} \mathrm{C}$, relative humidity of $50 \pm 10 \%$, and a 12 -h light cycle. All animal experiments were conducted in compliance with the Guidelines for Animal Experimentation issued by the Chinese Association for Laboratory Animal Science and the Standards Relating to the Care and Management of Experimental Animals throughout the study.

\section{Mutant G-CSF and Expression of G-CSFa in E. Coli}

G-CSF cDNA was obtained through reverse transcriptase-mediated polymerase chain reaction (RT-PCR) using total RNAs isolated from human monocytes. The primers used for PCR were as follows: upstream primer, 5' TGG ATC CAT GAC CCC CCT GGG CCC 3' and downstream primer, 5' TAA GAT CTC AAG CTT TCA GGG CTG CGC AAG GTG GCG TA3'. The amplified products were fractionated on agarose gels. The G-CSF cDNA eluted from the agarose gel was digested by Bam HI and Hind III, and ligated to plasmid pQE3 that had been cut with the same restriction enzymes. The ligation mixture was transformed into Escherichia coli JM109 competent cells for characterization of the cloned cDNA. Mutant G-CSF (G-CSF ${ }^{\mathrm{C} 17 \mathrm{~A}}$ ) was made by replacing codon TGC with codon GCC through site-direct mutagenesis. The identity of G-CSF cDNA, as well as the introduced mutation, was confirmed by a thorough DNA sequencing analysis. The pQE3 plasmid expressing mutant G-CSF (G-CSFa) was transformed into $E$. coli M15 cells for expression. Expression of G-CSFa was induced by isopropylthio- $\beta$ d-galactoside (IPTG).

\section{Refolding and purification of G-CSFa}

$E$. Coli pellets were disrupted with addition of lysozyme (5 mg/liter culture) in $0.1 \mathrm{M}$ TrisHCl buffer ( $\mathrm{pH} 8.0$ ). Inclusion body was collected by washing three times with an extraction buffer [50 mM TrisHCl ( $\mathrm{pH} 8.0), 2$ mM EDTA, $2 \mathrm{M}$ urea] and it was dissolved in a buffer containing a high concentration of urea $[50 \mathrm{mM}$ TrisHCl (pH 8.0), 2 mM EDTA, 8 M urea, 2\% DTT]. Refolding of recombinant G-CSFa was achieved by dialysis against $50 \mathrm{mM}$ TrisHCl buffer ( $\mathrm{pH}$ 8.0) for three times (12 h intervals). Refolded recombinant GCSFa was purified by anion exchange chromatography and size exclusion chromatography. Recombinant GCSFa was stored in $50 \mathrm{mM}$ acetic acid-sodium acetate buffer (pH 5.4) containing 5\% mannitol. Purified protein was also subjected to protein sequencing analysis using the Edman degradation method [13].

\section{Western blotting}

Protein samples fractionated on denaturing (SDS) polyacrylamide gels ( $4 \%$ stacking gel, $12 \%$ separating gel) were transferred to a polyvinylidene difluoride (PVDF) membrane. The membrane was blocked in a $2 \%$ bovine serum albumin (BSA) solution for $1 \mathrm{hr}$ and then incubated for $1 \mathrm{hr}$ with a monoclonal antibody to G-CSF (R \& D systems). After washing three times with a Tris $\mathrm{HCl}$ buffer, the membrane was incubated for $1 \mathrm{hr}$ with a goat-anti-mouse immunoglobulin G (IgG) conjugated with alkaline phosphatase. Specific signals on the membrane were visualized by addition of substrate, O-phenylene diamine (OPD).

\section{In vitro bioactivity assay}

In vitro activity of recombinant G-CSFa was determined using the murine myelobalstic cell line NFS-60 as originally described by Shirafuji [14]. We also employed this bioassay method as described above for measuring the activity of human G-CSF using NFS-60 cells. Recombinant G-CSF made in house as well as commercial one were used as positive controls.

\section{Animal neutropenia models}

BALB/CICR C57 male mice with an average weight of $22.5 \pm 1.2 \mathrm{~g}$ were irradiated with cesium-137 (4 Gy) using Gammacell-40 apparatus (Nurolion, Canada) to induce leukopenia. To induce leukopenia in Monkeys, animals were intravenously administered with cyclophosphamide at a dose of $50 \mathrm{mg} / \mathrm{kg} /$ day for 2 days.

\section{Measurement of mice bone marrow DNA content}

Mouse femur was cleaned and washed with $5 \mathrm{mM}$ $\mathrm{CaCl}_{2}$. Bone marrow cells were flushed out with a $10 \mathrm{ml}$ $5 \mathrm{mM} \mathrm{CaCl}_{2}$ solution. Bone marrow cells were placed at $4^{\circ} \mathrm{C}$ for $30 \mathrm{~min}$ and then centrifuged $(2,500 \mathrm{RPM} \times 15$ $\mathrm{min})$. The pellet was resuspended in $5 \mathrm{ml} 0.2 \mathrm{M} \mathrm{HClO}$, heated at $90^{\circ} \mathrm{C}$ for $15 \mathrm{~min}$, and filtrated through a 0.45 $\mu \mathrm{m}$ filter after cooling. DNA content was determined by measuring the absorbance of the solution at $260 \mathrm{~nm}$ $\left(\mathrm{A} 260_{\mathrm{nm}}\right)$ in a spectrophotometer.

\section{Cytology}

Monkey bone marrow was aspirated from the posterior iliac crest. Bone marrow slides were prepared in a 
fashion similar to the blood smears, which were subjected to routine Wright's staining. Peripheral white blood cells and neutrophils were counted using an automated hematology cell counter (Biochem Immunosystem).

\section{Statistical analysis}

Data obtained from mouse studies were subjected to statistical analysis using a $Q$ test. Data obtained from monkey studies were subjected to statistical analysis using a Newman-Keuls test. The results were considered statistically significant when $\mathrm{P}$ value was less than 0.05 .

\section{Results}

Structurally modified G-CSF (G-CSFa) was expressed in E. coli using a $\mathrm{pQE}$ vector expression system. Following the addition of IPTG, recombinant G-CSFa was highly induced (Figure 1). In fact, G-CSFa was the most predominant protein in the bacterial cell lysates after induction. Recombinant G-CSFa was subjected to extensive purification using a combination of biochemical approaches. SDS-PAGE analysis revealed that recombinant G-CSFa was purified to homogeneity and remained intact (Figure 1A). Immunoblotting analysis showed that the G-CSF antibody detected IPTG-induced G-CSFa in the total bacterial lysates as well as its the purified form (Figure 2), suggesting that the amino acid addition and substitution do not significantly change the overall conformation of protein. Protein sequencing analysis

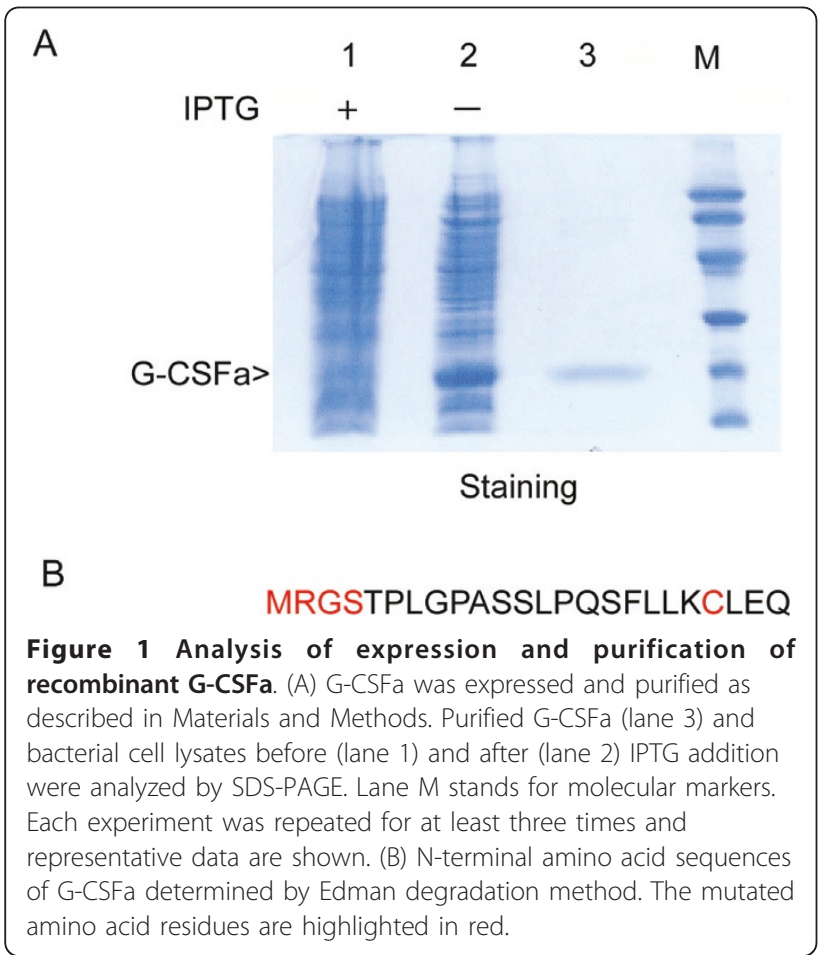

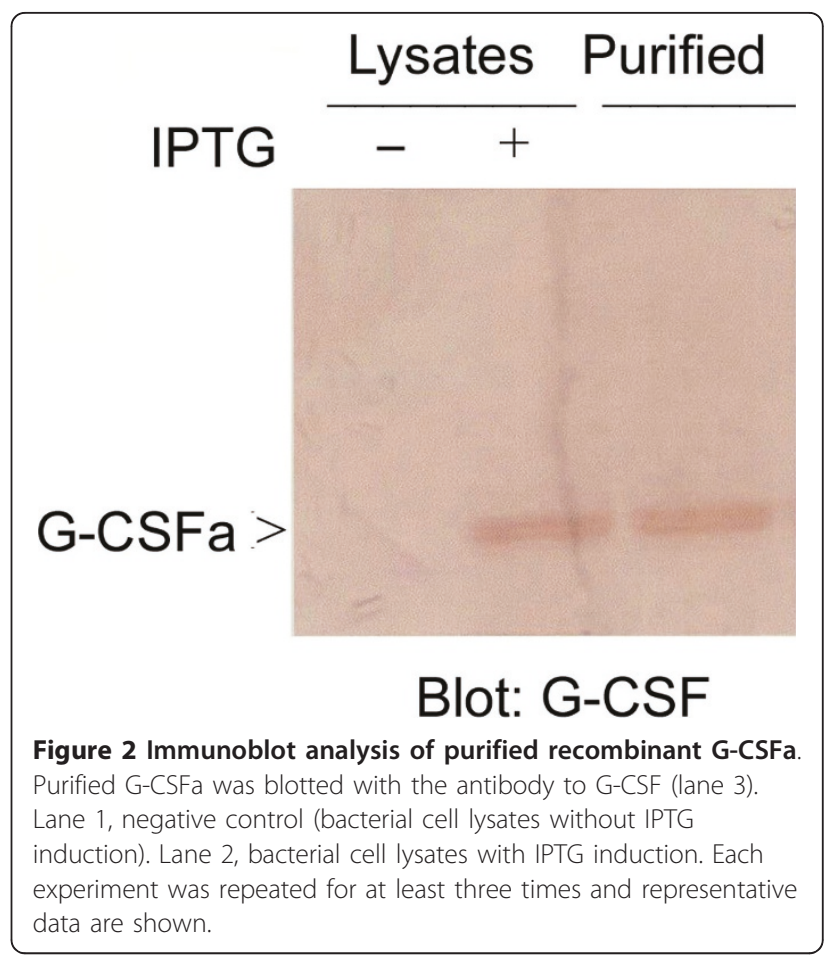

confirmed that the purified protein was the modified form of G-CSF with the addition of methionine, arginine, glycine, and serine residues at the amino-terminus and with cysteine-17 replaced by alanine as predicted (Figure 1B).

To determine the in vitro activity of purified G-CSFa, we employed a cell proliferation assay using NFS-60 cells as described [14]. We observed that the addition of G-CSFa greatly stimulated the proliferation rate of NFS60 cells (Figure 3 ). G-CSFa was more potent in

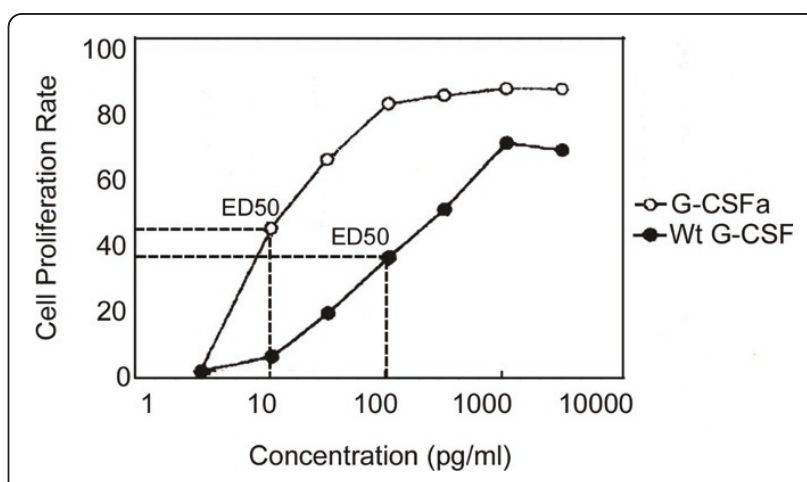

Figure 3 A comparison of in vitro activity between G-CSFa and wild-type G-CSF. Recombinant G-CSFa and G-CSF at indicated concentrations (10 pg, 20 pg, 100 pg, 200 pg, $1 \mu \mathrm{g}$, and $20 \mu \mathrm{g}$ per milliliter, respectively) were used for the stimulation of NFS-60 cell proliferation. The concentrations that stimulate $50 \%$ cell proliferation rate (ED50) were obtained for each cytokine. Each experiment was repeated for at least three times and similar results were obtained. 
stimulating the proliferation of NFS-60 cells than the wild-type recombinant G-CSF at the same concentrations (Figure 3). In fact, ED50 for G-CSFa was about 10-fold lower than that for wild-type G-CSF.

We next determined the in vivo activity of G-CSFa using the murine model. Irradiated mice were injected with wild-type G-CSF or with G-CSFa for 5 days as described in Materials and Methods. Peripheral white blood cell counts were determined at various times after cytokine injection. We observed that peripheral leukecytes in mice decreased drastically after irradiation and gradually increased to about $2 / 3$ of the original level during the course of three weeks. Similar to that of GCSF, G-CSFa was effective in stimulating the recovery of white blood cells in the irradiated mice (Figure 4; Table 1). At $50 \mu \mathrm{g} / \mathrm{ml}$ concentration, G-CSFa, but not G-CSF, was able to sustain an elevated white blood cell counts at day 26 and beyond. At day 34, which was six days after the cessation of cytokine administration, the white blood cell counts in peripheral blood of mice injected with G-CSFa remained at 128\% $(100 \mu \mathrm{g} / \mathrm{ml})$ and $113 \%$ $(50 \mu \mathrm{g} / \mathrm{ml})$ of the level before irradiation, respectively. On the other hand, wild-type G-CSF was unable to support the full recovery of white blood cells to the preirradiation level by day 26 and beyond (Figure 4; Table $1)$. Bone marrow cellularity was determined by measuring the total DNA content. After irradiation for 8 days, the total DNA content of the marrow cells from mice injected with G-CSFa or G-CSF was significantly higher

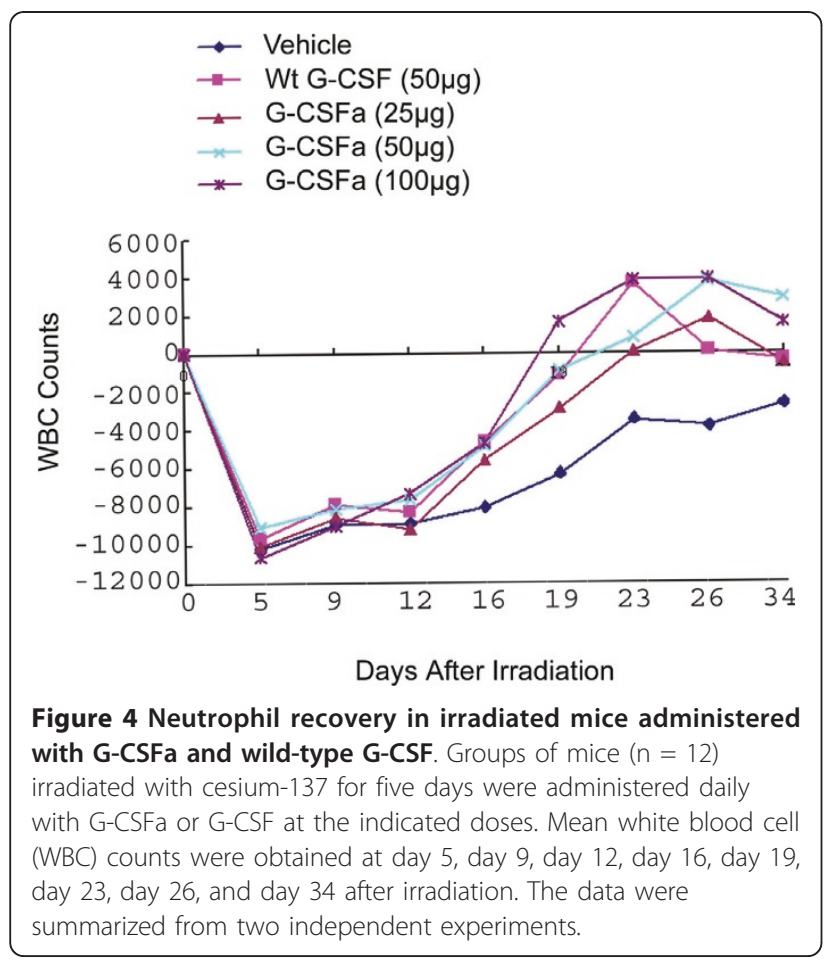

than that injected with vehicle although there was no significant difference in the DNA content between mice injected with G-CSF or G-CSFa (Table 2).

We next test the in vivo efficacy of G-CSFa in stimulating neutrophil production using the primate model. Anemic monkeys were obtained by the injection with cyclophosphamide (CTX) for 2 days at a dose of $50 \mathrm{mg} /$ $\mathrm{kg} /$ day. Five days after CTX injection, G-CSFa was administered daily via s.c. for successive 13 days. Wildtype of G-CSF at the same dose was administered into separate groups of monkeys as a positive control. Absolute neutrophil counts (ANC) in peripheral blood were determined at various times post cytokine treatment. ANC in control monkeys treated with the vehicle remained low for almost three weeks before bouncing back to the pretreatment level (Figure 5). In contrast, both G-CSF and G-CSFa were able to reduce both the degree and the duration of neutropenia, which were characterized by a dual-peak curve of neutrophil increase. The first peak appeared at day 7 and the second peak between day 12 and day 17. At day 7, G-CSFa, but not G-CSF, induced a significant (37\%) increase in neutrophils compared with the pretreatment level (Figure 5). Consistent with the mouse data, the effect of G-CSFa on neutrophil production lasted longer than that of G-CSF. After the cessation of cytokine administration at day 22, ANC in monkeys administered with G-CSFa (10 ug/kd/day), but not G-CSF (10 $\mu \mathrm{g} / \mathrm{kg} /$ day $)$, remained significantly above the pretreatment level with CTX.

We next directly examined neutrophil production in bone marrow of monkeys undergone various treatments. Microscopic examination revealed that the level of nucleated cells in monkeys administrated with vehicle alone was very low, consistent with the neutropenic condition induced by CTX (Figure 6). However, treatment with G-CSF resulted in a significant increase in the number of nucleated cells, most of which belong to the neutrophil lineage. Consistent with the ANC kinetics shown above, G-CSFa also stimulated the production of nucleated cells in bone marrow and the stimulation was more potent than G-CSF at the same dosage. Morphological analysis indicated that these cells were primarily neutrophils of various differentiation stages.

\section{Discussion}

G-CSF is a glycoprotein with a molecular mass of approximate $20 \mathrm{kDa}$. It is a bioactive molecule that has been extensively used in the clinic as a therapeutic agent for supporting the production of blood cells of the neutrophil linage [15]. It also displays biological effects on various aspects of hematopoiesis both in vivo and in vitro [8]. G-CSF has widely used in the clinic for over 15 years, primarily for accelerating neutrophil recovery 
Table 1 Effect of G-CSFa on white blood cell counts in irradiated C57 Mice $\left(10^{9} / L ; x \pm S D ; n=12\right)$

\begin{tabular}{|c|c|c|c|c|c|c|c|c|c|}
\hline \multirow[t]{2}{*}{ Groups } & \multirow{2}{*}{$\begin{array}{l}\text { Before } \\
\text { Treatment }\end{array}$} & \multicolumn{8}{|c|}{ Days After Irradiation } \\
\hline & & d5 & d9 & d12 & d16 & d19 & d23 & d26 & d34 \\
\hline Control & $11413 \pm 2089$ & $1233 \pm 553$ & $2450 \pm 1104$ & $2533 \pm 850$ & $3342 \pm 811$ & $5083 \pm 260$ & $7925 \pm 1667$ & $7575 \pm 1858$ & $8750 \pm 2203$ \\
\hline Wt G-CSF $(50 \mathrm{mg} / \mathrm{kg})$ & $10996 \pm 2731$ & $1342 \pm 337$ & $3100 \pm 1408$ & $2667 \pm 502$ & $6358 \pm 1398$ & $9858 \pm 2333^{a}$ & $14650 \pm 2861^{b}$ & $11092 \pm 2319^{a}$ & $10592 \pm 1547$ \\
\hline 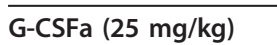 & $11083 \pm 2724$ & $855 \pm 342$ & $2508 \pm 923$ & $1900 \pm 972$ & $5483 \pm 973$ & $8192 \pm 2721$ & $11192 \pm 4593^{a}$ & $12917 \pm 2921^{b}$ & $10533 \pm 1741$ \\
\hline G-CSFa $(50$ mg/kg) & $10178 \pm 4014$ & $1100 \pm 412$ & $2042 \pm 687$ & $2508 \pm 565$ & $5325 \pm 1139$ & $9250 \pm 3766^{a}$ & $10975 \pm 3052^{\mathrm{a}}$ & $13950 \pm 3087^{b}$ & $13075 \pm 3120^{a}$ \\
\hline G-CSFa $(100 \mathrm{mg} / \mathrm{kg})$ & $11814 \pm 3802$ & $1175 \pm 344$ & $2783 \pm 1233$ & $4483 \pm 1394$ & $6325 \pm 1726$ & $13467 \pm 4719^{b}$ & $15650 \pm 3572^{b}$ & $15700 \pm 4278^{b}$ & $13383 \pm 2696$ \\
\hline
\end{tabular}

a: $p<0.05$, b: $p<0.01$ vs. Control Group 
Table 2 DNA content of mouse bone marrow cells

\begin{tabular}{|c|c|}
\hline Groups & $\mathrm{OD}_{260 \mathrm{~nm}}$ \\
\hline Vehicle & $0.65+0.12$ \\
\hline Wt G-CSF $(50 \mu \mathrm{g} / \mathrm{kg})$ & $1.01+0.34^{*}$ \\
\hline G-CSFa $(25 \mu \mathrm{g} / \mathrm{kg})$ & $0.95+0.13^{*}$ \\
\hline G-CSFa $(50 \mu \mathrm{g} / \mathrm{kg})$ & $1.01+0.14^{*}$ \\
\hline G-CSFa $(100 \mu \mathrm{g} / \mathrm{kg})$ & $1.02+0.20^{*}$ \\
\hline
\end{tabular}

Irradiated (4 Gy) mice were administered daily via s.c. with cytokine or vehicle as indicated. Left femur was obtained for bone marrow cell collection. These cells were subsequently processed for analysis of total DNA contents. *: $p<$ 0.01 vs. vehicle

in cancer patients with myelo-suppressive chemotherapy or radiotherapy $[9,10]$. G-CSF is a glycoprotein although glycosylation is not essential for its bioactivity. Clinical studies have demonstrated that recombinant non-glycosylated G-CSF expressed in and purified from E. coli displays almost the same therapeutic efficacy as glycosylated form of G-CSF $[11,16]$. Native G-CSF contains five cysteine residues. They form two internal disulfide bonds (Cys36-Cys42 and Cys64-Cys74), leaving one cysteine residue (Cys17) with a free sulfhydryl group. It is conceivable that this free cysteine residue may pose some problems during G-CSF purification and refolding. Firstly, the presence of Cys17 may increase the frequency of mismatch during the formation of intra-

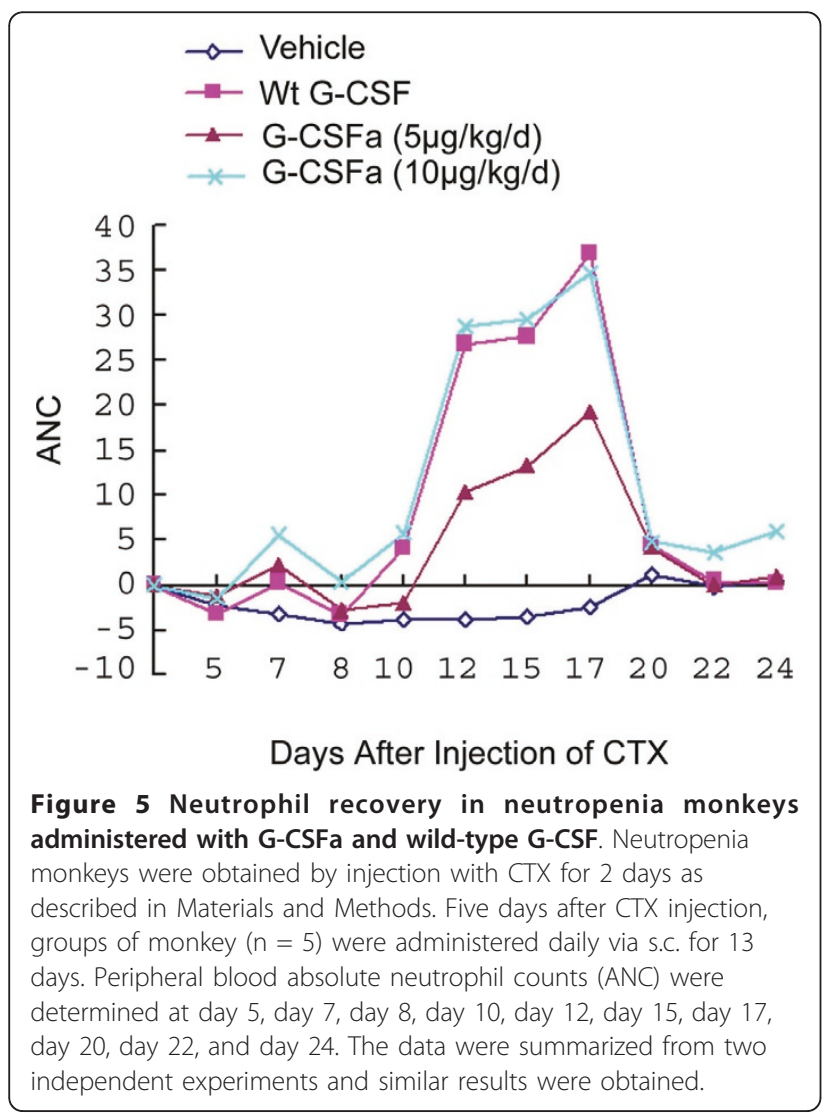

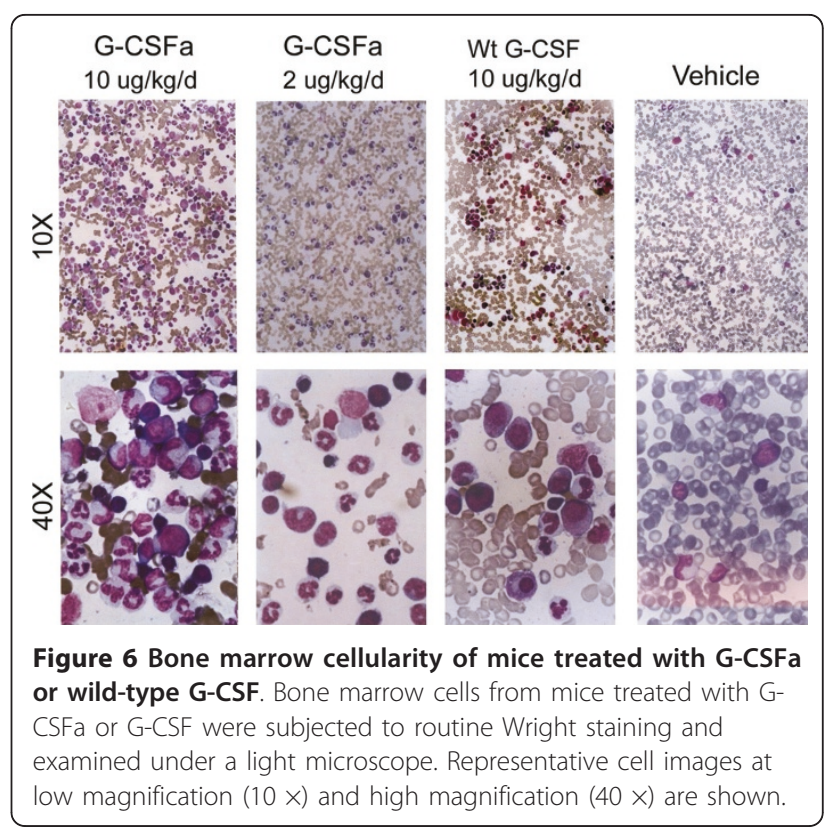

molecular disulfide bonds, resulting in a reduced yield of refolding. Secondly, it is possible that the free sulfhydryl group in cysterine residues may interfere with the stability of G-CSF. In other words, Cys17 may form inter-molecular disulfide bonds, resulting in the formation of G-CSF oligomers under certain oxidized condition. Oligomerization can conceivably lead to a decrease in the availability of G-CSF.

We reason that the substitution of cysteine 17 with alanine may result in an enhanced bioavailability and bioactivity of G-CSF, possibly through the elimination of oligomerization caused by the formation of inter-molecular disulfide bonds. In fact, our cell-based assays and in vivo studies in both mice and monkeys are consistent with the notion. Significantly, as evidenced from the examination of the first peak of neutrophil increase (Figure 5), G-CSFa induced a much higher level of ANC than G-CSF did. Although it is relative small this increase is of great value for patients receiving myelosuppressive therapies. It is the period when patients are most susceptible to infections due to drastic neutrophil reduction. Therefore, a shortened window in which patients have low neutrophil counts will greatly facilitate them to combat deleterious infections. Further supporting this notion, a separate pharmacokinetic study reveals that G-CSFa exhibits both better stability in vitro and higher bioavailability in vivo than wild-type G-CSF [17].

G-CSF exerts its activity through the interaction with its receptor (G-CSF-R). Upon binding to G-CSF-R, GCSF induces a signal transduction cascade in target cells, leading to various biological manifestations including cell proliferation and differentiation. G-CSF 
belongs to the long chain family of cytokines with an anti-parallel 4-helix bundles and long overhand loops. The major binding site on G-CSF has been shown to include residues in $\mathrm{A}$ and $\mathrm{C}$ helices $[18,19]$. Further studies indicates that Glu19 in the A helix of G-CSF molecule electrostatically inter-reacts with Arg288 of G-CSF-R $[20,21]$. A recent study on the crystal structure of G-CSF, complexed with the cytokine homologous region of G-CSF-R, reveals that residues in the amino-terminus of G-CSF may act as additional contact sites with G-CSF-R, which is unstructured in the unbound protein [22]. In this respect, the addition of arginine, glycine, and serine residues in the amino-terminus of G-CSFa that results in a more positive charge in the amino-terminus of G-CSFa may further enhance the binding between the cytokine and its receptor. This may also contribute to the higher bioactivity observed with the mutant G-CSF. It is conceivable that the tighter binding to its cognate receptor may render G-CSFa to be dissociated from its receptor at a slower rate, resulting in a longer time of action both in vivo and in vitro. In fact, G-CSF with a single amino acid substitution (Cys17 to Ala17) shows a better stability in plasma [17]. Therefore, we believe that the same mutation in G-CSFa also contributes to the enhanced bioactivities.

During the past decade or so, great efforts have been directed to finding a more stable and thus more effective G-CSF because of its instability in vivo. PEGylated G-CSF has been reported to enhance the stability of this cytokine. However, the steric hindrance effect of PEGylated proteins significantly suppresses the specific binding of PEGylated proteins to their cognate receptors or substrates [23]. Besides, pegylation calls for an additional modification step after obtaining purified target protein, which makes the production process inconvenient and adds costs to the production. In the current study, we report that G-CSFa exhibits an enhanced bioactivity due likely to its better stability. As a chronic toxicity study shows that G-CSFa does not exhibit significant toxicity and immunogenicity in rats [24], this cytokine derivative can be further explored for the development of a new generation of therapeutic agents for patients with neutropenia.

\section{Acknowledgements}

We thank Dr. Yiqi Zhou for useful discussion. This work is supported in part by grants from Ministry of Science \& Technology of China (Grant \# 2004AA001036), State Scientific Key Projects for New Drug Research and Development (2009ZX09102-250), and High-tech Research Project for Medicine and Pharmacology of Jiangsu province (BG20070605).

\section{Author details}

${ }^{1}$ Fanzhou Biopharmagen Corporation, Suzhou, China. ${ }^{2}$ New York University School of Medicine, Tuxedo, NY, USA.

\section{Authors' contributions}

YJ was involved in experimental designs, data acquisition and analysis data interpretation as well as drafting manuscript. YQ carried out protein purification experiments and was involved in data acquisition, analysis and interpretation. WJ conducted in vitro experiments including protein purification and analysis. WD was involved in the analysis and interpretation of data as well as manuscript preparation.

The authors read and approved the manuscript.

\section{Competing interests}

The authors declare that they have no competing interests.

Received: 29 April 2011 Accepted: 13 June 2011

Published: 13 June 2011

\section{References}

1. Dong F, van Buitenen C, Pouwels K, Hoefsloot LH, Lowenberg B, Touw IP: Distinct cytoplasmic regions of the human granulocyte colonystimulating factor receptor involved in induction of proliferation and maturation. Mol Cell Biol 1993, 13(12):7774-7781.

2. Souza LM, Boone TC, Gabrilove J, Lai PH, Zsebo KM, Murdock DC, Chazin VR, Bruszewski J, Lu H, Chen KK, et al: Recombinant human granulocyte colony-stimulating factor: effects on normal and leukemic myeloid cells. Science 1986, 232(4746):61-65.

3. Panopoulos AD, Watowich SS: Granulocyte colony-stimulating factor: molecular mechanisms of action during steady state and 'emergency' hematopoiesis. Cytokine 2008, 42(3):277-288.

4. Bober LA, Grace MJ, Pugliese-Sivo C, Rojas-Triana A, Waters T, Sullivan LM, Narula SK: The effect of GM-CSF and G-CSF on human neutrophil function. Immunopharmacology 1995, 29(2):111-119.

5. de Haas M, Kerst JM, van der Schoot CE, Calafat J, Hack CE, Nuijens JH, Roos D, van Oers RH, von dem Borne AE: Granulocyte colony-stimulating factor administration to healthy volunteers: analysis of the immediate activating effects on circulating neutrophils. Blood 1994, 84(11):3885-3894.

6. Gottlieb RA, Giesing HA, Zhu JY, Engler RL, Babior BM: Cell acidification in apoptosis: granulocyte colony-stimulating factor delays programmed cell death in neutrophils by up-regulating the vacuolar $\mathrm{H}(+)$-ATPase. Proc Natl Acad Sci USA 1995, 92(13):5965-5968.

7. Lopez AF, Williamson DJ, Gamble JR, Begley CG, Harlan JM, Klebanoff SJ, Waltersdorph A, Wong G, Clark SC, Vadas MA: Recombinant human granulocyte-macrophage colony-stimulating factor stimulates in vitro mature human neutrophil and eosinophil function, surface receptor expression, and survival. J Clin Invest 1986, 78(5):1220-1228.

8. Basu S, Dunn A, Ward A: G-CSF: function and modes of action (Review). Int J Mol Med 2002, 10(1):3-10.

9. Aso $\mathrm{Y}$, Akaza $\mathrm{H}$ : Effect of recombinant human granulocyte colonystimulating factor in patients receiving chemotherapy for urogenital cancer. Urological rhG-CSF Study Group. J Urol 1992, 147(4):1060-1064.

10. Schmidberger H, Hess CF, Hoffmann W, Reuss-Borst MA, Bamberg M: Granulocyte colony-stimulating factor treatment of leucopenia during fractionated radiotherapy. Eur J Cancer 1993, 29A(14):1927-1931.

11. Carlsson G, Ahlin A, Dahllof G, Elinder G, Henter Jl, Palmblad J: Efficacy and safety of two different rG-CSF preparations in the treatment of patients with severe congenital neutropenia. Br J Haematol 2004, 126(1):127-132.

12. Kroger N, Zander AR: Dose and schedule effect of G-GSF for stem cell mobilization in healthy donors for allogeneic transplantation. Leuk Lymphoma 2002, 43(7):1391-1394.

13. Edman P: Sequence determination. Mol Biol Biochem Biophys 1970, 8:211-255.

14. Shirafuji N, Asano S, Matsuda S, Watari K, Takaku F, Nagata S: A new bioassay for human granulocyte colony-stimulating factor (hG-CSF) using murine myeloblastic NFS-60 cells as targets and estimation of its levels in sera from normal healthy persons and patients with infectious and hematological disorders. Exp Hematol 1989, 17(2):116-119.

15. Komrokji RS, Lyman GH: The colony-stimulating factors: use to prevent and treat neutropenia and its complications. Expert Opin Biol Ther 2004, 4(12):1897-1910.

16. Chamorey AL, Magne N, Pivot X, Milano G: Impact of glycosylation on the effect of cytokines. A special focus on oncology. Eur Cytokine Netw 2002, 13(2):154-160. 
17. Liu XX, Jiang YP: Pharmacokinetic study of a novel recombinant human granulocyte colony-stimulating factor in rats. Chin Med Sci J 2010, 25(1):13-19.

18. Reidhaar-Olson JF, De Souza-Hart JA, Selick HE: Identification of residues critical to the activity of human granulocyte colony-stimulating factor. Biochemistry 1996, 35(28):9034-9041.

19. Young DC, Zhan H, Cheng QL, Hou J, Matthews DJ: Characterization of the receptor binding determinants of granulocyte colony stimulating factor. Protein Sci 1997, 6(6):1228-1236.

20. Layton JE, Hall NE, Connell F, Venhorst J, Treutlein HR: Identification of ligand-binding site III on the immunoglobulin-like domain of the granulocyte colony-stimulating factor receptor. J Biol Chem 2001, 276(39):36779-36787.

21. Layton JE, Shimamoto G, Osslund T, Hammacher A, Smith DK, Treutlein HR, Boone T: Interaction of granulocyte colony-stimulating factor (G-CSF) with its receptor. Evidence that Glu19 of G-CSF interacts with Arg288 of the receptor. J Biol Chem 1999, 274(25):17445-17451.

22. Aritomi M, Kunishima N, Okamoto T, Kuroki R, Ota Y, Morikawa K: Atomic structure of the GCSF-receptor complex showing a new cytokinereceptor recognition scheme. Nature 1999, 401(6754):713-717.

23. Clark R, Olson K, Fuh G, Marian M, Mortensen D, Teshima G, Chang S, Chu H, Mukku V, Canova-Davis E: Long-acting growth hormones produced by conjugation with polyethylene glycol. J Biol Chem 1996, 271(36):21969-21977.

24. Xia F, Zhang QY, Jiang YP: Chronic toxicity of a novel recombinant human granulocyte colony-stimulating factor in rats. Chin Med Sci J 2011, 26(1):20-27.

doi:10.1186/1756-8722-4-28

Cite this article as: Jiang et al.: Effect of a structurally modified human granulocyte colony stimulating factor, G-CSFa, on leukopenia in mice and monkeys. Journal of Hematology \& Oncology 2011 4:28.

\section{Submit your next manuscript to BioMed Central and take full advantage of:}

- Convenient online submission

- Thorough peer review

- No space constraints or color figure charges

- Immediate publication on acceptance

- Inclusion in PubMed, CAS, Scopus and Google Scholar

- Research which is freely available for redistribution

Submit your manuscript at www.biomedcentral.com/submit 